\title{
Detecção de SARS-CoV-2 na saliva e em glândulas salivares - uma revisão
}

\section{sistemática}

\author{
Detection of SARS-CoV-2 in saliva and salivary glands - a systematic review \\ Detección de SARS-CoV-2 en saliva y glándulas salivales- una revisión sistemática
}

\author{
Lavínia Bonfim Sampaio \\ ORCID: https://orcid.org/000-0002-1042-7070 \\ Escola Bahiana de Medicina e Saúde Pública, Brasil \\ E-mail: laviniasampaio18.2@bahiana.edu.br \\ Bruna Carvalho Lopez Moreno \\ ORCID: https://orcid.org/000-00002-7936-1970 \\ Escola Bahiana de Medicina e Saúde Pública, Brasil \\ E-mail: brunamoreno20.1@bahiana.edu.br \\ Anildo Alves de Brito Junior \\ ORCID: https://orcid.org/000-0002-7752-3104 \\ Faculdade Adventista da Bahia, Brasil \\ E-mail: junioranildo02@gmail.com. \\ Flávia Quadros Lima \\ ORCID: https://orcid.org/0000-0001-9269-1037 \\ Escola Bahiana de Medicina e Saúde Pública, Brasil \\ E-mail: flaviaquadros.pos@bahiana.edu.br \\ Juliana Borges de Lima Dantas \\ ORCID: https://orcid.org/0000-0002-9798-9016 \\ Escola Bahiana de Medicina e Saúde Pública, Brasil \\ Faculdade Adventista da Bahia, Brasil \\ E-mail: julianadantas.pos@bahiana.edu.br. \\ Alena Ribeiro Alves Peixoto Medrado \\ ORCID: https://orcid.org/0000-0003-4074-4680 \\ Escola Bahiana de Medicina e Saúde Pública, Brasil \\ E-mail: apmedrado@bahiana.edu.br
}

\begin{abstract}
Resumo
No início da pandemia de COVID-19 foi observado que o contato com a saliva infectada representava uma forma de contágio possivelmente relacionada com a proximidade anatômica entre o trato respiratório superior e a cavidade oral. Estudos recentes indicam que o SARS-COV-2 pode infectar células epiteliais das glândulas salivares, o que impacta na prática clínica de cirurgiões-dentistas. O presente trabalho objetivou coletar evidências acerca da presença de SARSCoV-2 em glândulas salivares, da sua detecção por meio da saliva e discutir a relevância deste conhecimento na prática clínica odontológica. Foi realizada uma revisão sistemática com busca nas bases de dados Pubmed, Lilacs, Google Schoolar, Scielo, Cochrane e Medline, no período entre novembro/2020 a maio/2021. Foram adotadas as diretrizes PRISMA e o anagrama PICO para caracterização dos estudos de acordo com os critérios de inclusão, que compreenderam estudos prospectivos sobre a temática, com texto completo online disponível em inglês ou português, e publicados a partir de 2020. Entre os 17 artigos selecionados, 2 estudos prospectivos avaliaram a presença de SARSCoV-2 no parênquima de glândulas salivares e todos os 16 trabalhos constataram a presença de SARS-CoV-2 na saliva. $\mathrm{O}$ tamanho da amostra variou de acordo com o tipo de estudo, e o total de participantes foi 3677. Este estudo ratifica a saliva como uma via de transmissão e, sendo assim, é crucial que todos os profissionais de saúde utilizem os equipamentos de proteção individual e tenham rigor com as normas de biossegurança.
\end{abstract}

Palavras-chave: Covid-19; Glândula salivar; Saliva e infecção.

\begin{abstract}
At the beginning of the COVID-19 pandemic, contact with the saliva infected was observed to represent a form of contagion possibly related to the anatomical proximity between the upper respiratory tract and the oral cavity. Studies seem to indicate that SARS-COV-2 can infect epithelial cells of the salivary glands, and impacts the clinical practice of dental surgeons. This study aimed to collect current evidence on the presence of SARS-CoV-2 in salivary glands, its detection through saliva, and discuss the relevance of this knowledge in clinical dental practice. A systematic review was conducted in the databases Pubmed, Lilacs, Google Schoolar, Scielo, Cochrane and Medline in the period from November/2020 to May/2021. PRISMA guidelines and the anagram PICO were adopted to characterize the selected studies according to the inclusion criteria, which comprised prospective studies, with full text available online in the English or Portuguese language and published from the year 2020. Among the 17 selected articles, 2 prospective studies
\end{abstract}


evaluated the presence of SARS-CoV-2 in the parenchyma of salivary glands and all 16 papers found the presence of SARS-CoV-2 in saliva. The size of the studies varied according to the type of study, and the total number of participants was 3677 . This study ratifies saliva as a route of transmission, and it is crucial that all health care workers use personal protective equipment and adhere strictly to biosafety regulations.

Keywords: Covid-19; Salivary gland; Saliva and infection.

\section{Resumen}

Ya la pandemia de COVID-19 se observó que el contacto con la saliva infectada representaba una forma de contagio relacionada con la proximidad anatómica entre el tracto respiratorio superior y la cavidad oral. Estudios indicar que el SARS-COV-2 puede infectar las células epiteliales de las glándulas salivales, con un profundo impacto en la práctica clínica de los cirujanos dentales. Este estudio tenía como objetivo recopilar las pruebas sobre la presencia del SARSCoV-2 en las glándulas salivales, su detección a través de la saliva y discutir la relevancia de estos conocimientos en la práctica clínica dental. Esta revisión sistemática se realizó una búsqueda en las bases de datos Pubmed, Lilacs, Google Schoolar, Scielo, Cochrane y Medline en el periodo entre noviembre/2020 y mayo/2021. Se adoptaron las directrices PRISMA y el anagrama PICO para caracterizar los estudios según los criterios de inclusión, que comprendían estudios con texto completo disponible en inglés y portugués, publicados a partir del año 2020. Entre los 17 artículos seleccionados, 2 estudios evaluaron la presencia de SARS-CoV-2 en el parénquima de las glándulas salivales y los 16 trabajos encontraron la presencia de SARS-CoV-2 en la saliva. El tamaño de la muestra variaba según el tipo de estudio, y el número total de participantes era de 3.677. Este estudio ratifica que la saliva es una vía de transmisión y, por lo tanto, es crucial que todos los profesionales sanitarios utilicen equipos de protección personal y cumplan rigurosamente las normas de bioseguridad.

Palabras clave: Covid-19; Glándula salival; Saliva y infección.

\section{Introdução}

A pandemia do coronavírus da síndrome respiratória aguda grave 2 (SARS-Cov-2), originada em Wuhan, província da China, em dezembro de 2019, gerou grande preocupação na comunidade científica internacional, não só em razão de sua alta transmissibilidade, mas também por estar associada a uma considerável taxa de mortalidade. De acordo com a Organização Mundial de Saúde (OMS), na atualização operacional semanal sobre a COVID-19 de 28 de janeiro de 2022, foram confirmados 364.191.494 de casos, e 5.631.457 mortes (OMS, 2022). Neste momento, faz-se necessário ampliar o conhecimento acerca da doença, bem como do seu controle e uma possível profilaxia, através de uma abordagem vacinal eficaz.

A magnitude desta pandemia está relacionada primariamente ao fato de sua transmissão se dar por gotículas de saliva e também pelas secreções respiratórias. Segundo Azzi et al. (2020), há evidência da presença de altos títulos do coronavírus da síndrome respiratória aguda grave 2 (SARS-CoV-2) na saliva e nas secreções das vias respiratórias que chegam até a cavidade oral através do reflexo da tosse.

Segundo Benvenuto et al. (2020), Huang et al. (2020) e Chen et al. (2020), o SARS-CoV-2 é semelhante, em alguns aspectos estruturais e de comportamento biológico, a outros coronavírus já isolados, a exemplo do SARS-CoV-1 de 2002 e do MERS, de 2012. De acordo com Hoffman et al. (2020), devido à similaridade entre tais vírus, o SARS-CoV-2 utiliza a mesma via de entrada nas células humanas que o SARS-CoV-1, que se dá através da interação do patógeno a um receptor de membrana denominado angiotensina-convertase II (ACE2). Além dessa via de sinalização, Hoffman et al. (2020), evidenciaram que as espículas do envelope do SARS-CoV-2 podem se ligar também a uma serina protease transmembranar 2 (TMPRSS2) presente na membrana da célula hospedeira para a ativação de proteína S. O receptor ACE2 e a serina protease TMPRSS2 são essenciais para o vírus estabelecer uma interação com a superfície da proteína $\mathrm{S}$ e para se fusionar à membrana com consequente entrada na célula hospedeira (Burgueño-Rodrigues et al., 2020). Tanto a ACE2 quanto a TMPRSS2 estão presentes em diversos tipos celulares do corpo humano. A TMPRSS2 tem sido expressa por células endoteliais (Kumar et al., 2020), além de ser também altamente expressa nas glândulas pituitária e próstata (Song et al., 2020). Por outro lado, a ACE2 está expressivamente presente nas células dos alvéolos pulmonares, nos rins, na mucosa oral (Xu et al., 2020), testículos, intestino delgado e tecido adiposo (Song et al., 2020) e células endoteliais de vasos sanguíneos e capilares (Kumar et al., 2020). Evidência mais recente também 
indica que ambos os receptores, ACE2 e TMPRSS2, são significativamente expressos nas células epiteliais da mucosa oral e das glândulas salivares (Song et al., 2020).

Em um estudo experimental com ratos, Song et al. (2020), constataram que a considerável expressão da ACE2 e TMPRSS2 na membrana das células ductais e acinares de glândulas salivares, parece sugerir que o vírus pode se reproduzir no interior destas e essa localização anatômica poderia representar um sítio de replicação viral ativo alternativo aumentando a carga viral na saliva, além daqueles presentes nas células do aparelho respiratório.

Diante do exposto, tem aumentado o interesse por esse possível reservatório a fim de compreender melhor a patogênese da infecção pelo SARS-CoV-2. Em especial, esse conhecimento será relevante para os cirurgiões-dentistas, haja visto que estes profissionais lidam diretamente com a cavidade oral. Muitas vezes, os cirurgiões-dentistas entram em contato com portadores assintomáticos que podem apresentar uma carga viral significativa na mucosa oral e na saliva em razão da possível replicação viral no interior das glândulas salivares. Este aspecto já foi previamente documentado por Wang et al. (2004). Tais autores demonstraram que o SARS-CoV-1 pode ser detectado na saliva antes mesmo de existirem lesões nos pulmões.

A presente revisão sistemática objetivou compilar evidências científicas atuais acerca da presença de SARS-CoV-2 em glândulas salivares e na saliva e discutir a relevância deste conhecimento na prática clínica odontológica.

\section{Metodologia}

\subsection{Desenho do estudo}

Tratou-se de uma revisão sistemática qualitativa que foi elaborada de acordo com a metodologia PRISMA (Principais Itens para relatar Revisões sistemáticas e Meta-análises). Este estudo foi submetido à plataforma PROSPERO, com número de registro CRD42021235096 e objetivou responder à seguinte pergunta central: "Quais são as evidências científicas da presença de SARS-CoV-2 na saliva não aspirada e no parênquima de glândulas salivares?”

\subsection{Estratégia de Busca}

Foi realizada uma busca por estudos publicados em revistas científicas indexadas, nas bases de dados eletrônicas Scielo, Pubmed, Cochrane, BVS (Biblioteca Virtual em Saúde) e Google Acadêmico. O período de busca compreendeu os meses de novembro de 2020 a maio de 2021. Foram utilizados os seguintes descritores especificados no DeCS/MESH "Glândulas Salivares", "Saliva", "COVID-19" e "SARS-CoV-2" e seus correspondentes na língua inglesa, "Salivary Glands", "Saliva", "Covid-19" e "SARS-CoV-2", através das seguintes combinações: "Glândulas Salivares E Covid-19", "Glândulas Salivares E SARS-CoV-2", “Glândulas Salivares E Covid-19 E SARS-CoV-2", ”Saliva E Covid-19", "Saliva E SARS-CoV-2", "Saliva E Covid-19 E SARS-CoV-2", , "Salivary Glands AND Covid-19", "Salivary Glands AND SARS-CoV-2" e "Salivary Glands AND Covid-19 AND SARS-CoV-2", "Saliva AND Covid-19", "Saliva AND SARS-CoV-2" e "Saliva AND Covid-19 AND SARSCoV-2".

\subsection{Critérios de Elegibilidade}

Os critérios de inclusão compreenderam estudos de acurácia diagnóstica e prospectivos, incluindo estudos de corte transversal, coorte, ensaios clínicos randomizados e não randomizados, que avaliaram a COVID-19 e possível presença do SARS-CoV-2 na saliva não expectorada e em glândulas salivares. Os manuscritos selecionados deveriam estar disponíveis online, sob a forma de texto completo, nos idiomas português e inglês e publicados a partir do ano de 2020. Os artigos publicados em anos anteriores, revisões de literatura, relatos de caso clínico e aqueles que fugissem à temática proposta, não foram incluídos na presente revisão. Estudos que contemplaram a análise da saliva estimulada por tosse ou expectorada, não foram incluídos na presente revisão. 
Os artigos selecionados de acordo com os critérios de inclusão e não inclusão foram analisados independentemente por dois avaliadores. Quaisquer divergências entre estes foram resolvidas por consenso. O nível de concordância entre os dois autores revisores foi avaliado através do índice Cohen kappa, com valor 0,95 .

\subsection{Análise de Qualidade}

Os dados referentes à população, objetivo, metodologia, ano, tipo do estudo, resultados e desfecho foram extraídos independentemente pelos dois avaliadores e sumarizados em uma tabela descritiva desenvolvida especialmente para esta revisão sistemática. A escala de qualidade STROBE (Strengthening the Reporting of Observational Studies in Epidemiology) também foi utilizada, atribuindo uma classificação para cada item da escala: item totalmente atendido, parcialmente atendido/ Conformidade do item não está claro. Aqueles que atenderam aos critérios de qualidade nesta revisão sistemática tiveram pelo menos 17 itens classificados como total ou parcialmente atendidos.

\subsection{Extração de Dados}

Para a extração dos dados dos estudos utilizou-se o anagrama PICO, onde foi definida a população de indivíduos com suspeita de infecção pelo SARS-CoV-2; a intervenção incluiu a realização de exames laboratoriais para detecção do SARS-CoV2 na saliva e em glândulas salivares; foram considerados controles aqueles sem infecção; e o desfecho foi a detecção do vírus na saliva e/ou no parênquima de glândulas salivares.

\subsection{Estratégia de Síntese de Dados}

Os dados foram sintetizados pelo método de síntese temática. Foi realizada análise da heterogeneidade clínica e da heterogeneidade metodológica dos manuscritos por meio do teste de heterogeneidade. Todos os dados foram resumidos em uma tabela descritiva e qualitativa desenvolvida especialmente para esta revisão sistemática.

\section{Resultados}

Inicialmente, foram identificados 163 artigos por meio de pesquisa nas seguintes bases de dados online seguindo a estratégia de busca: 9 no Pubmed, 65 no BVS, 26 no Scielo e 63 no Google acadêmico. Além disso, foi realizada uma busca ativa para outros estudos citados nas referências dos artigos identificados no primeiro levantamento, que culminou na inclusão de mais 15 estudos. No processo de triagem, 51 artigos duplicados foram excluídos. Cento e dez estudos foram excluídos após a leitura dos títulos e resumos segundo as seguintes justificativas: 73 não responderam à pergunta central, 7 eram estudos experimentais, 3 relatos de caso clínico, 21 revisões de literatura e 6 não possuíam texto disponível em inglês. Após todas as eapas de refinamento, 17 artigos foram selecionados e considerados elegíveis. O fluxograma 1 ilustra a estratégia de busca. 
Fluxograma 1 - Estratégia de busca dos artigos de acordo com os critérios de inclusão. Período de busca: Novembro de 2020 até Maio de 2021. Salvador, Bahia.
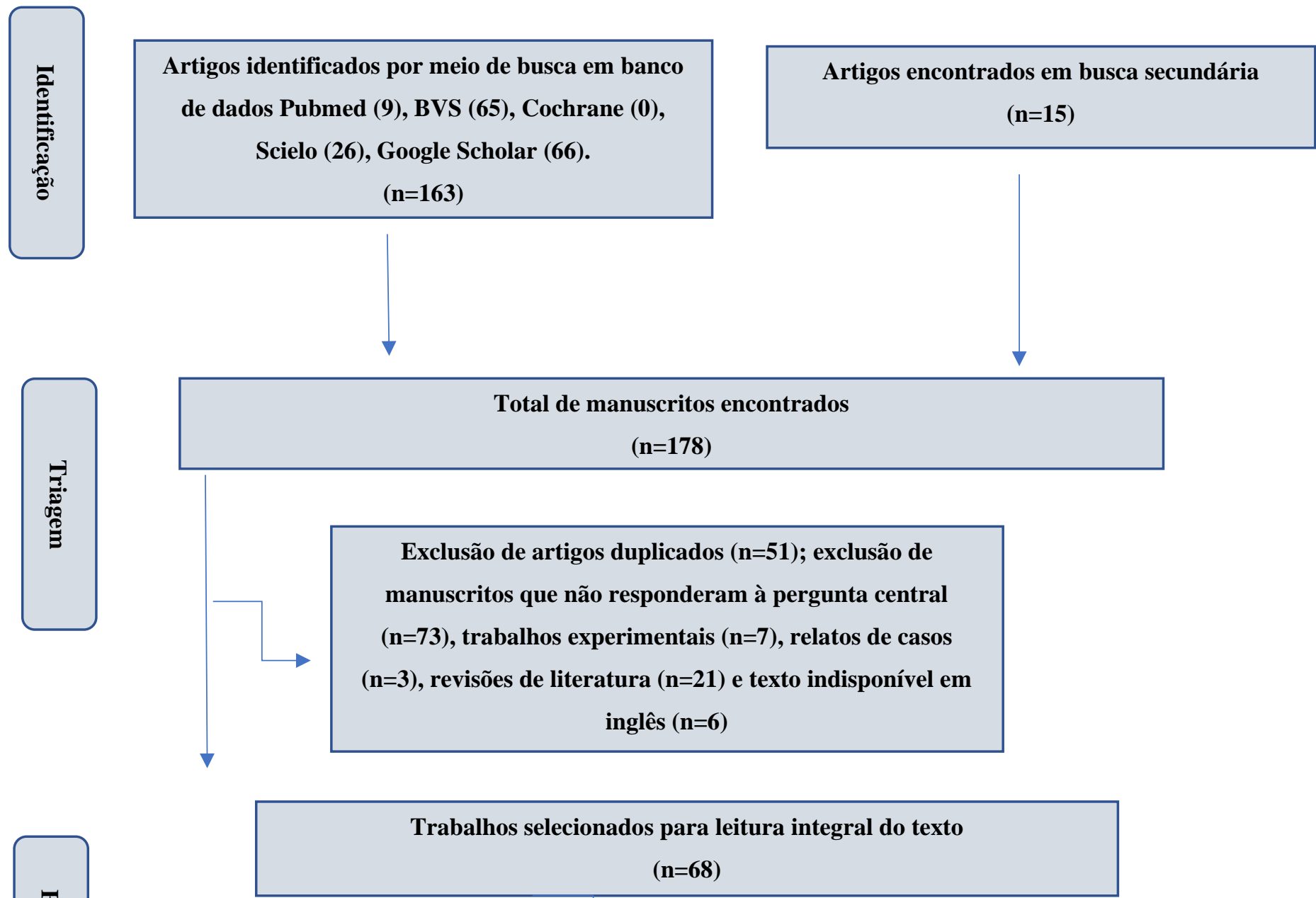

Não atenderam aos critérios de qualidade estabelecidos da escala STROBE

(51)

Artigos incluídos

$(n=17)$

\section{Artigos com texto completo}

$(n=17)$ 
Com relação à análise da qualidade metodológica dos artigos incluídos, optou-se por selecionar aqueles com pontuação acima de $70 \%$ na escala STROBE.

Tabela 1 - Avaliação da qualidade metodológica de artigos utilizando a escala STROBE (Strengthening the Reporting of Observational Studies in Epidemiology), onde ${ }^{\circ}$ corresponde a item atendido pelo artigo e $\mathbf{X}$, parcialmente atendido pelo artigo ou a conformidade com o item não foi clara.

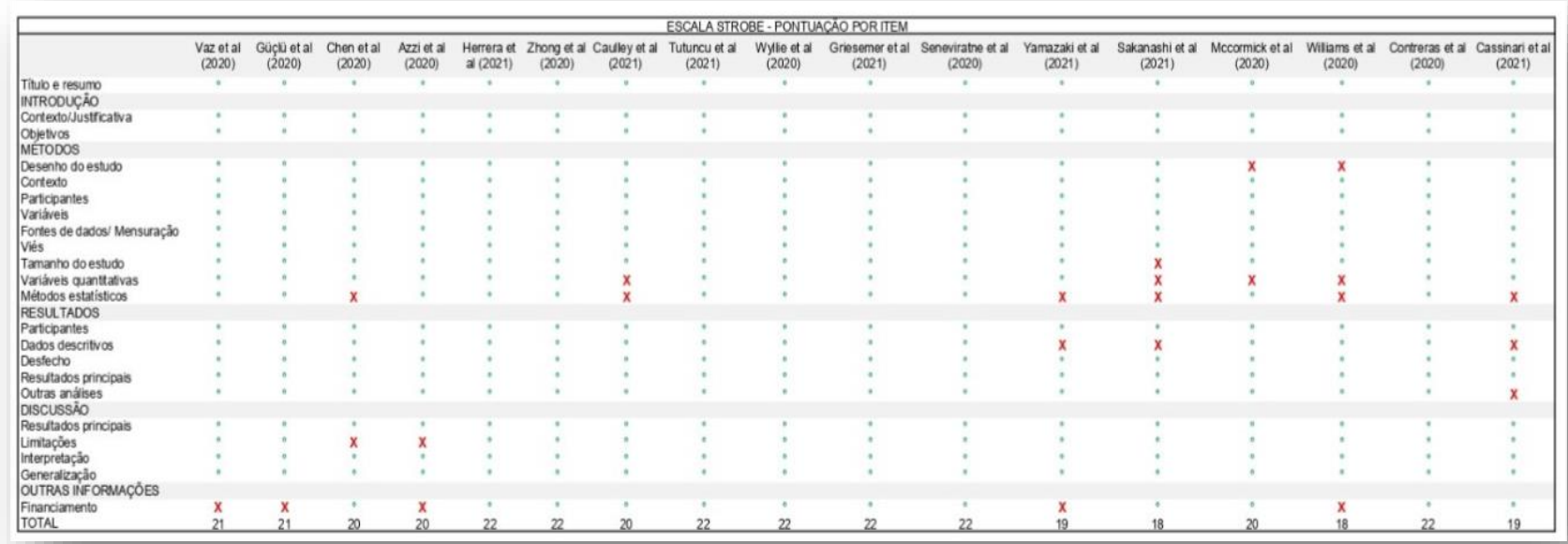

Fonte: Autores.

Entre os 17 manuscritos selecionados, 2 estudos prospectivos avaliaram a presença de SARS-CoV-2 no parênquima de glândulas salivares e todos os estudos catalogados avaliaram a presença de SARS-CoV-2 na saliva. O tamanho da amostra variou de acordo com o tipo de cada estudo, e o total de participantes foi de 3677. As características dos estudos selecionados estão descritas a Tabela 2 .

Tabela 2: Síntese dos manuscritos selecionados. Período de busca: novembro de 2020 até maio de 2021. Salvador. Bahia. Brasil.

\begin{tabular}{|c|c|c|c|c|c|}
\hline Título & $\begin{array}{c}\text { Periódico } \\
\text { Autores }\end{array}$ & Objetivo & População Metodologia & Resultados & Conclusão \\
\hline $\begin{array}{l}\text { Saliva is a realiable } \\
\text { non- invasive } \\
\text { speciment for } \\
\text { SARS-COV-2 } \\
\text { detection }\end{array}$ & $\begin{array}{l}\text { Braz J Infect } \\
\text { Dis } \\
\text { Vaz et al. } \\
\text { (2020) }\end{array}$ & $\begin{array}{l}\text { Validar a utilização } \\
\text { da saliva como } \\
\text { amostra biológica } \\
\text { para o diagnóstico } \\
\text { de COVID-19. }\end{array}$ & $\begin{array}{l}(\mathrm{n}=155) \\
\text { Participantes } \\
\text { apresentaram } \\
\text { sinais/sintomas } \\
\text { sugeestivos de infecção } \\
\text { por SARS- CoV-2 foram } \\
\text { submetidos à coleta com } \\
\text { swab nasofaríngeo (NPS) } \\
\text { e /ou swab orofaríngeo } \\
\text { (OPS) e coleta de saliva. } \\
\text { Amostras de saliva foram } \\
\text { submetidas a RT- Real } \\
\text { Time PCR para SARS- } \\
\text { Cov-2. }\end{array}$ & $\begin{array}{l}\text { A sensibilidade do RT-PCR } \\
\text { com amostras de saliva foi de } \\
94,4 \% \text { (IC 95\% 86,4-97,8) e } \\
97,62 \% \text { (IC 95\% 91,7-99,3), } \\
\text { respectivamente. Houve alta } \\
\text { concordância geral }(96,1 \% \text { ) } \\
\text { entre os dois testes. }\end{array}$ & $\begin{array}{l}\text { Amostras de saliva } \\
\text { coletadas pela própria } \\
\text { pessoa é uma alternativa } \\
\text { fácil, conveniente e de } \\
\text { baixo custo aos testes } \\
\text { moleculares baseados em } \\
\text { swab nasofaríngeo. Esses } \\
\text { resultados podem permitir } \\
\text { um uso mais amplo de } \\
\text { testes moleculares para o } \\
\text { manejo da pandemia de } \\
\text { COVID-19, especialmente } \\
\text { em locais com recursos } \\
\text { limitados. }\end{array}$ \\
\hline $\begin{array}{l}\text { Comparision of } \\
\text { saliva and } \\
\text { oronasopharyngeal } \\
\text { swab sample in the } \\
\text { molecular diagnosis } \\
\text { of COVID- } 19\end{array}$ & $\begin{array}{c}\text { Rev Assoc Med } \\
\text { Bras } \\
\text { Güçlü et al. } \\
\text { (2020) }\end{array}$ & $\begin{array}{c}\text { Comparar os } \\
\text { métodos de coleta } \\
\text { de saliva e swab de } \\
\text { naso e orofaringe } \\
\text { (ONS) }\end{array}$ & $\begin{array}{l}(\mathrm{n}=64) \\
\text { Pacientes foram } \\
\text { divididos nos grupos } 1,2 \\
\text { e 3: G1 - pacientes com } \\
\text { diagnóstico de COVID- } \\
19 \text { confirmado pela } \\
\text { reação em cadeia da } \\
\text { polimerase (PCR); G2 - } \\
\text { achados compatíveis com } \\
\text { COVID-19 em } \\
\text { tomografia }\end{array}$ & $\begin{array}{l}\text { O SARS- Cov- } 2 \text { foi detectado } \\
\text { em } 27(42,2 \%) \text { amostras de } \\
\text { saliva dos pacientes. Enquanto a } \\
\text { sensibilidade e o valor preditivo } \\
\text { positivo das amostras de saliva } \\
\text { foi de } 85,2 \% \text {, a especificidade e } \\
\text { o valor preditivo negativo foi } \\
89,2 \% \text { O valor de Kappa } \\
\text { apresentou concordância } \\
\text { substancial } \\
(0.744), \quad \text { sendo }\end{array}$ & $\begin{array}{l}\text { As amostras de saliva } \\
\text { podem ser usadas em vez de } \\
\text { amostras de região de } \\
\text { nasofaringe na detecção de } \\
\text { SARS- CoV-2. Investigar o } \\
\text { SARS- CoV-2 com saliva é } \\
\text { mais barato, mais fácil para } \\
\text { o paciente em geral, é mais } \\
\text { importante, pois apresenta } \\
\text { menor risco de } \\
\text { contaminação do SARS- }\end{array}$ \\
\hline
\end{tabular}


Research, Society and Development, v. 11, n. 3, e45111326673, 2022

(CC BY 4.0) | ISSN 2525-3409 | DOI: http://dx.doi.org/10.33448/rsd-v11i3.26673

\begin{tabular}{|c|c|c|c|c|c|}
\hline & & & $\begin{array}{l}\text { computorizada (TC) de } \\
\text { pulmão, mas com PCR } \\
\text { negativo; G3 - pacientes } \\
\text { que se apresentaram à } \\
\text { emergência com queixas } \\
\text { compatíveis, mas com } \\
\text { TC normal. Amostras de } \\
\text { saliva e de nasofaringe } \\
\text { foram coletadas no } 3^{\circ} \text { dia } \\
\text { de sintomas nos G1 e G2, } \\
\text { enquanto no G3, foram } \\
\text { coletadas na admissão } \\
\text { hospitalar. }\end{array}$ & $\begin{array}{l}\text { estaticamente } \\
(<0.001)\end{array}$ & $\begin{array}{l}\text { CoV-2 para os profissionais } \\
\text { de saúde. }\end{array}$ \\
\hline $\begin{array}{l}\text { Detection of SARS- } \\
\text { CoV-2 in saliva and } \\
\text { characterization of } \\
\text { oral symptoms in } \\
\text { COVID-19 patients }\end{array}$ & $\begin{array}{c}\text { Cell } \\
\text { Proliferation } \\
\text { Chen et al. } \\
\text { (2020) }\end{array}$ & $\begin{array}{l}\text { Realizar uma análise } \\
\text { de perfis de RNA- } \\
\text { seq de bancos de } \\
\text { dados públicos e } \\
\text { também uma } \\
\text { pesquisa por } \\
\text { questionário sobre } \\
\text { sintomas orais em } \\
\text { pacientes com } \\
\text { COVID -19. }\end{array}$ & 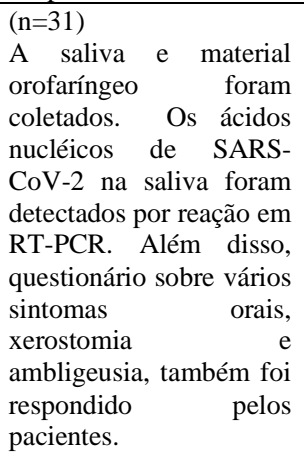 & $\begin{array}{l}\text { Dos } 4 \text { casos com detecção } \\
\text { positiva de ácidos nucléicos de } \\
\text { SARS-CoV-2 na saliva, três } \\
(75 \%) \text { estavam gravemente } \\
\text { enfermos com suporte } \\
\text { ventilatório. Além disso, } \\
\text { relatou-se que os dois principais } \\
\text { sintomas orais, xerostomia } \\
(46,3 \%) \text { e ambligeusia (47,2\%), } \\
\text { foram manifestados por uma } \\
\text { proporção relativamente alta de } \\
108 \text { pacientes com COVID-19 } \\
\text { que responderam } \\
\text { questionário. }\end{array}$ & $\begin{array}{l}\text { Este estudo confirmou a } \\
\text { expressão de ACE2 nas } \\
\text { glândulas salivares e } \\
\text { demonstrou a possibilidade } \\
\text { de infecção por SARS- } \\
\text { CoV-2 nas glândulas } \\
\text { salivares. }\end{array}$ \\
\hline $\begin{array}{l}\text { Saliva is a realiable } \\
\text { tool to detect SARS- } \\
\text { CoV-2 }\end{array}$ & $\begin{array}{l}\text { J Infect } \\
\text { Azzi et al. } \\
(2020)\end{array}$ & $\begin{array}{l}\text { Analisar amostras } \\
\text { salivares de } \\
\text { pacientes com } \\
\text { COVID- } 19 \mathrm{e} \\
\text { comparar os } \\
\text { resultados com seus } \\
\text { dados clínicos e } \\
\text { laboratoriais. }\end{array}$ & 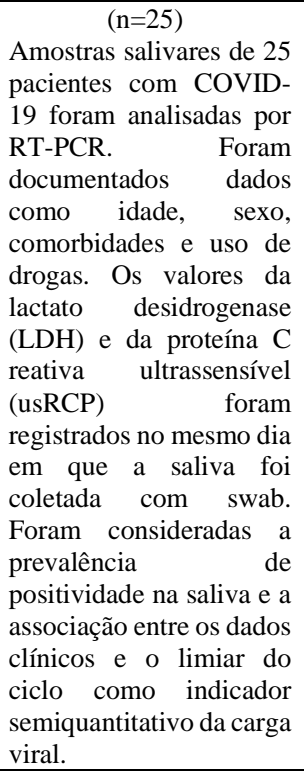 & $\begin{array}{l}\text { Todas as amostras apresentaram } \\
\text { resultados positivos para a } \\
\text { presença de SARS-CoV-2. Dois } \\
\text { pacientes apresentaram } \\
\text { resultados positivos na saliva } \\
\text { nos mesmos dias em que seus } \\
\text { swabs faríngeos ou respiratórios } \\
\text { mostraram conversão. }\end{array}$ & $\begin{array}{l}\text { A saliva é uma ferramenta } \\
\text { confiável para detectar } \\
\text { SARS- CoV-2. O papel da } \\
\text { saliva no diagnóstico da } \\
\text { COVID-19 não se limita a } \\
\text { uma detecção qualitativa de } \\
\text { vírus, mas também pode } \\
\text { fornecer informações sobre } \\
\text { a evolução clínica da } \\
\text { doença. }\end{array}$ \\
\hline $\begin{array}{c}\text { Saliva is a realible } \\
\text { and accessible } \\
\text { source for the } \\
\text { detection of SARS- } \\
\text { CoV-2 }\end{array}$ & $\begin{array}{l}\text { Int J Infect Dis } \\
\text { Herrera et al. } \\
\quad(2021)\end{array}$ & $\begin{array}{l}\text { Comparar a } \\
\text { reprodutibilidade, } \\
\text { precisão e } \\
\text { viabilidade da } \\
\text { amostragem de } \\
\text { saliva seguida por } \\
\text { RT-qPCR para } \\
\text { identificar SARS- } \\
\text { CoV-2 e avaliar o } \\
\text { uso de saliva em } \\
\text { estratégias de } \\
\text { agrupamento de } \\
\text { amostras. }\end{array}$ & \begin{tabular}{l}
\multicolumn{2}{c}{$(\mathrm{n}=210)$} \\
As amostras foram \\
pareadas e coletadas de \\
indivíduos \\
assintomáticos da área de \\
saúde e de trabalhadores \\
de escritório na cidade do \\
México. O \\
processamento da \\
amostra e a análise do \\
material genético do \\
vírus foram realizados.
\end{tabular} & $\begin{array}{l}\text { A concordância entre } \\
\text { os resultados de material } \\
\text { coletado em nasofaringe (NPS) } \\
\text { e a saliva foi de } 95,2 \% \text { (kappa } \\
0,727 \text {, p=0,0001) e } 97,9 \% \text {, } \\
\text { respectivamente (p=0,0001). A } \\
\text { saliva teve um número menor de } \\
\text { resultados inconclusivos do que } \\
\text { o NPS ( } 0,9 \% \text { vs } 1,9 \%) \text {. Além } \\
\text { disso, mostrou concentração } \\
\text { maior de RNA total e de cópias } \\
\text { virais do que o NPS. A } \\
\text { comparação dos resultados com } \\
\text { os outros dois laboratórios } \\
\text { mostraram } 100 \% \text { e } 97 \% \text { de } \\
\text { concordância. }\end{array}$ & $\begin{array}{l}\text { A saliva é tão eficaz quanto } \\
\text { o material coletado em } \\
\text { nasofaringe para a } \\
\text { identificação de pacientes } \\
\text { assintomáticos infectados } \\
\text { com SARS- CoV-2. }\end{array}$ \\
\hline $\begin{array}{l}\text { Continuously high } \\
\text { detection sensitivity } \\
\text { of saliva, viral } \\
\text { shedding in salivary } \\
\text { glands and high } \\
\text { viral load in } \\
\text { pacientes with } \\
\text { COVID-19 }\end{array}$ & $\begin{array}{l}\text { The Lancet } \\
\text { Zhong et al. } \\
(2020)\end{array}$ & $\begin{array}{c}\text { Esclarecer a } \\
\text { sensibilidade dos } \\
\text { testes em detectar o } \\
\text { SARS-CoV-2 na } \\
\text { saliva, a eliminação } \\
\text { viral nas glândulas } \\
\text { salivares, a carga } \\
\text { viral durante a }\end{array}$ & $\begin{array}{l}\text { (n=49) } \\
\text { Os bancos de dados } \\
\text { GTEx e TCGA foram } \\
\text { usados para análise de } \\
\text { expressão de ACE2. } \\
\text { Foram obtidos esfregaços } \\
\text { faríngeos, orais, e retais; } \\
\text { amostras de sangue e }\end{array}$ & $\begin{array}{l}\text { Um total de } 538 \text { amostras foram } \\
\text { obtidas. A taxa de detecção de } \\
\text { SARS-CoV-2 por casos } \\
\text { positivos em saliva, esfregaços } \\
\text { orais, faríngeos, retais e sangue } \\
\text { foi de } 90,2 \%(37 / 41), 49,0 \% \\
\begin{array}{lll}(24 / 49), 83,7 \% & (41 / 49), & 63,6 \% \\
(14 / 22) \text { e } 17,4 \% & (4 / 23),\end{array}\end{array}$ & $\begin{array}{l}\text { A saliva representa uma } \\
\text { amostra melhor para } \\
\text { detecção de SARS-CoV-2, } \\
\text { pois o exame apresentou } \\
\text { alta sensibilidade e houve } \\
\text { economia de tempo. A alta } \\
\text { expressão de ACE2, a alta } \\
\text { taxa de detecção de RNA de }\end{array}$ \\
\hline
\end{tabular}




Efficacy of
comercial mouth-
rinses on SARS-
CoV-2 viral load in
saliva: randomized
control trial in
Singapore

Infection
Seneviratne et
al. (2020)
três bochechos al. (2020) comerciais com iodo povidona (PI) e gluconato de clorexidina (CPC) na redução da carga viral SARS- CoV-2 salivar em pacientes com COVID-19 em comparação com a água.
Avaliar a eficácia de

\begin{abstract}
$(n=36)$
Um total de 36 pacientes com SARS-CoV-2 foi recrutado, dos quais 16 pacientes foram aleatoriamente designados para 4 grupos-grupo PI $(n=4)$, grupo CHX ( $\mathrm{n}=6)$, grupo CPC $(n=4)$ e água como grupo controle $(n=2)$. Amostras de saliva foram coletadas dos pacientes no início do estudo e $5 \mathrm{~min}, \quad 3$ e $6 \mathrm{~h}$ após aplicação de enxaguatórios bucais/ água. Foi realizado RTPCR para detecção de SARS-CoV-2.
\end{abstract}

\begin{tabular}{cc}
\hline Saliva samples for & J Med Virol \\
detection of SARS- & \\
CoV-2 in mildly & Tutuncu, Ozgur \\
symptomatic and & e Karamese \\
asymptomatic & $(2021)$ \\
patients &
\end{tabular}

Avaliar o $\quad(\mathrm{n}=53)$

diagnóstico de amostras de saliva em pacientes com sintomas moderados e assintomáticos, com Covid-19

confirmado.

Saliva is more

New England J
Med
Wyllie et al.
(2020).

Amostras de saliva dos pacientes foram analisadas por RT- PCR.

\section{$(\mathrm{n}=44)$}

Para validar o uso de saliva para detecção de SARS-CoV-2, foram testadas amostras de nasofaringe e saliva de sensitive for SARSCoV-2 detection in COVID-19 patients than nasopharyngeal swabs

em esfregaços nasofaríngeos

pareados e amostras de saliva coletadas de pacientes internados com COVID-19 e profissionais de saúde

assintomáticos com risco moderado a alto de exposição a COVID-19.

\begin{tabular}{|c|c|c|}
\hline $\begin{array}{c}\text { Evaluation of } \\
\text { Specimen Types and } \\
\text { Saliva Stabilization } \\
\text { Solutions for SARS- } \\
\text { CoV-2 Testing }\end{array}$ & $\begin{array}{l}\text { J Clin Microb } \\
\text { Griesemer et al. } \\
\text { (2021). }\end{array}$ & $\begin{array}{l}\text { Investigar tipos de } \\
\text { espécimes } \\
\text { alternativos e saliva } \\
\text { que fornecem } \\
\text { sensibilidade de } \\
\text { detecção semelhante } \\
\text { com menor } \\
\text { exposição dos } \\
\text { profissionais de } \\
\text { saúde e potencial } \\
\text { para auto-coleta. }\end{array}$ \\
\hline
\end{tabular}

Development of a
point-of-care test to
detect SARS-CoV-2
from saliva which
combines a simple
RNA extraction
method with
colorimetric reverse
transcription loop-
mediated isothermal
amplification
detection

J Clin Virol
Yamazaki,
Matsumura,
Thongchankaew
-Seo, Yamazaki
e Nagao (2021).

preliminarmente o

desempenho do teste em 44 amostras

clínicas de saliva utilizando uma

RT- LAMP que faz

leitura colorimétrica

de um bloco de calor, com

infecção e a
alteração dos
exames laboratoriais
após o início dos
sintomas.

saliva para comparação da detecção de vírus. A carga viral foi determinada por RTqPCR. de SARS- CoV-2

respectivamente. A taxa de detecção por tempos positivos foi de $83,3 \%$ (70/84), 40,5\% $(30 / 74) \quad 53,7 \% \quad(130 / 242)$ $52,7 \%(49 / 93)$ e $8,9 \%(4 / 45)$ respectivamente. A saliva teve a taxa de detecção mais alta após início da infecção.

Não foram relatadas diferenças significativas na comparação dos grupos.

Entre os 53 pacientes com As amostras de saliva SARS- CoV-2 detectado na podem ser consideradas amostra de nasofaringe, o RT- uma alternativa confiável e PCR em tempo real foi positivo menos invasiva para o nas amostras de saliva em 48 rastreamento de infecções $(90,56 \%)$ pacientes. pacientes confirmados com COVID-19 e

amostras auto- coletadas de profissionais de saúde em enfermarias de COVID- 19.

\section{$(n=463)$}

A sensibilidade de detecção do SARS- CoV2 em esfregaços nasais (NS) e de saliva foi comparada com a as de nasofaringe (NPS) utilizando amostras correspondentes de dois ambulatórios do estado de New York.

\section{$(n=44)$} abordagem triplex

resultados avaliados a olho nu.

SARS- CoV-2 na saliva e eliminação contínua de vírus nas glândulas salivares sugerem infecção por SARS- CoV-2 nas glândulas salivares.

Observou-se que o efeito da redução da carga salivar com enxágue bucal com Clorexidina e iodo povidona se manteve após 6 horas. Os autores sugerem que o uso de tais colutórios sob a forma de bochechos comerciais pode ser útil como pré-procedimento para ajudar a reduzir a transmissão do COVID-19. assintomáticas por SARSCoV-2.

A sensibilidade da detecção do SARS- CoV-2 na saliva é comparável, senão superior aos esfregaços nasofaríngeos no início da hospitalização e é mais consistente durante a hospitalização prolongada e a recuperação.

A primeira coorte apresentou apenas $5,4 \%$ de positividade para o SARS-CoV-2, mas a segunda coorte $(n=227)$ teve taxa de positividade de $41 \%$ com sensibilidade da ordem de $97,9 \%$ para NPS, $87,1 \%$ para NS e $87,1 \%$ para saliva. Amostras de NS e saliva simultaneamente resultou em $94,6 \%$ de sensibilidade para detecção de SARS- CoV-2.

Foi detectada sensibilidade Pacientes com suspeita diagnóstica de 82,6\% (19/23) e de infecção de COVID19 realizaram o teste proposto, o qual durou 45 minutos. Para detectar o COVID-19 em campo, um teste point-of-care (POCT) foi usado na saliva. especificidade de $100 \%$ (21/21), em comparação com o padrão de referência.

\section{Os resultados} indicam que o uso da saliva para detecção de SARSCoV-2 é mais sensível e consistente do que o uso de swabs nasofaríngeos.

No geral, foi demonstrado que a saliva deve ser considerada como um tipo de amostra confiável para aliviar as demandas dos testes COVID-19.

\begin{abstract}
A combinação de SN e saliva viabilizou semelhante ao NPS. Os autores encorajam o uso desse tipo de amostra mista e sugerem que seja testada em uma variedade de plataformas e através de diferentes protocolos de atendimento.
\end{abstract} recentemente desenvolvida propiciou extração simples de RNA a partir da saliva. Os autores sugerem que este tipo de exame pode ser usado em estações de inserção simples em um ambiente de campo, ajudando a reduzir o risco de infecção ao simplificar e acelerar os testes para COVID-19.
A abordagem POCT 


\begin{tabular}{|c|c|c|}
\hline $\begin{array}{c}\text { Comparative } \\
\text { evaluation of } \\
\text { nasopharygeal swab } \\
\text { and saliva } \\
\text { speciments for the } \\
\text { molecular detection } \\
\text { of SARS-CoV-2 } \\
\text { RNA in japanise } \\
\text { pacientes with }\end{array}$ & $\begin{array}{c}\text { Journal of } \\
\text { Infection and } \\
\text { Chemotherapy } \\
\text { Sakanash et al. } \\
\text { (2021). }\end{array}$ & $\begin{array}{c}\text { Investigar o uso da } \\
\text { saliva como amostra } \\
\text { obtida de forma não } \\
\text { invasiva para a } \\
\text { detecção molecular } \\
\text { de RNA do SARS- } \\
\text { CoV-2 em pacientes } \\
\text { japoneses com } \\
\text { COVID-19. }\end{array}$ \\
\hline
\end{tabular}

\section{$(\mathrm{n}=12)$}

No total, 28 amostras clínicas pareadas de saliva e esfregaço nasofaríngeo foram coletados de 12 pacientes em vários momentos após o início dos sintomas. Cada amostra foi testada usando RTPCR.
As amostras de saliva e esfregaço nasofaríngeos apresentaram 19 e 15 resultados positivos, respectivamente. Os resultados qualitativos de cada espécime obtido no período imediatamente após o início dos sintomas foram semelhantes. Três pacientes convalescentes apresentaram resultados positivos para a saliva enquanto seus swabs nasofaríngeos foram negativos em 4 momentos diferentes, sugerindo que a saliva pode ser superior aos swabs nasofaríngeos em termos de obtenção de resultado de ensaio estável de SARS- CoV2.

\begin{tabular}{ccc}
\hline Saliva as an & J Clin Microbiol & Validar amostras de \\
Alternate Speciment & & saliva para o \\
Source of Detection & McComick- & diagnóstico de \\
of SARS- CoV-2 in & Baw et al. & COVID-19 usando o \\
Symptomatic & $(2020)$. & teste de PCR \\
Patients Using & & Cepheid Xpert \\
Cepheid Xpert & & Xpress SARS- CoV- \\
SARS- CoV-2. & & 2(Sunnyvale, CA).
\end{tabular}

$(\mathrm{n}=156)$

As amostras de saliva foram comparadas às amostras da região de nasofaringe (NPS). As amostras de saliva foram provenientes do departamento de emergência e de pacientes hospitalizados com COVID-19. As coletas de maneira padrão e, da mesma forma, os testes foram realizados de acordo com as instruções do fabricante. amostras de NPS foram
A positividade geral foi de 50/156 (32,1\%). A taxa de positividade da comunidade durante a semana de $11,1 \%$. Um total de 153/156 (98\%; intervalo de confiança de $95 \%$ [IC]. $94,48 \%$ a $99,60 \%$ ) amostras estavam em concordância geral. Além disso, 47/49 amostras foram positivas na saliva em comparação com o NPS, resultando em uma concordância percentua positiva de $96 \%$ (IC de $95 \%$ $86,02 \%$ a $99,5 \%$ ). Um total de $105 / 106$ amostras teve um resultado negativo de saliva e NPS. Uma única amostra demonstrou níveis detectáveis de ácido nucleico SARS- CoV2 na saliva, mas o NPS foi negativo (1/106), resultando em uma concordância percentual negativa de 99\% (IC95\%, $94,86 \%$ a $99,98 \%$ )

\begin{tabular}{cc}
\hline Saliva as a & J Clin Microbiol \\
Noninvasive & \\
Specimen for & Williams, Bond, \\
Detection of SARS- & Zhang, Putland \\
CoV-2 & e Williamson
\end{tabular}
No geral, 39/622 (6,3\% intervalo de confiança de $95 \%$ [IC], 4,6\% a $8,5 \%$ ) pacientes exibiram RT-PCR positivo com NPS e $33 / 39$ pacientes $(84,6 \%$; IC de $95 \%, 70,0$ a 93,1$)$ (2020).

$\begin{array}{cl}\text { Investigar a } & (\mathrm{n}=39) \\ \text { viabilidade e a } & 622 \text { pacientes foram } \\ \text { utilidade da coleta } & \text { testados para COVID-19. } \\ \text { de saliva de } & \text { Todos tinham esfregaços } \\ \text { pacientes } & \text { de nasofaringe (NPS), e } \\ \text { mbulatoriais que se } & 522 / 622(83,9 \%) \text { também } \\ \text { apresentaram a uma } & \text { forneceram saliva. }\end{array}$
apresentaram a uma COVID-19 em Melbourne,

Austrália. Saliva Sampling an ysis, an Excellent Option To increase the Number of SARS- CoV-2

Diagnostic Tests in Settings with Supply Shortages. Evidenciar que as amostras de saliva

J Clin Microbiol
Moreno-
Contreras et al.
(2020)
lisadas diretamente podem servir como uma fonte adequada para a detecção de RNA viral, que são menos dispendiosas e podems ser tão eficientes quanto o protocolo clássico

\section{$(n=253)$}

Amostras pareadas de esfregaços orofaríngeos e nasofaríngeos (OPSs e NPSs, respectivamente) e saliva foram coletados durante um período de 30 dias por profissionais de saúde. apresentaram SARS- CoV-2 detectado na saliva.

Dos 182 pacientes com um único esfregaço coletado, 80 $(43,9 \%)$ foram positivos para SARS-CoV-2. Destes, 41 $(51,2 \%)$ apresentaram PCR positivo para os dois tipos de amostras, enquanto $28 \quad(35 \%)$ foram positivos apenas com saliva e não com o esfregaço nasofaríngeo; e $11 \quad(13,7 \%)$ foram positivos apenas com o OPS. No total, dos 80 indivíduos considerados positivos para o vírus, 69 $(86,2 \%)$ foram identificadas corretamente pela saliva, enquanto apenas 52 (65\%) foram identificados pelo OPS. Os resultados sugerem que a saliva pode servir potencialmente como uma alternativa aos esfregaços nasofaríngeos como uma amostra para a realização de RT-PCR para SARSCoV-2.

A saliva é uma alternativa aceitável para a detecção de ácidos nucléicos do SARSCoV-2. Outra vantagem da saliva em relação ao NPS é que o processo de coleta de saliva não é invasivo, e um paciente, com educação e treinamento, pode coletar as amostras por conta própria.
Foram demonstradas a viabilidade, aceitabilidade e escalabilidade da coleta prospectiva de saliva de pacientes ambulatoriais. Os autores sugerem que a saliva representa uma mostra não invasiva para a detecção de SARS- CoV-2.

Os resultados indicam que um processamento rápido de saliva usando lise direta com tampão parece ser uma excelente alternativa para a análise de RNA do SARSCoV-2. Trata-se de um método sensível, rápido e barato que pode ser usado para triagem massiva e particularmente, naqueles ambientes onde os suprimentos comuns necessários para os métodos clássicos estão em falta.

Para as amostras de esfregaço de nasofarínge 


\begin{tabular}{|c|c|c|c|c|c|}
\hline $\begin{array}{l}\text { Droplet RT-PCR as } \\
\text { a Diagnostic Tool } \\
\text { for SARS- CoV-2 } \\
\text { Detection in } \\
\text { Nasopharygeal } \\
\text { Swabs and Saliva } \\
\text { Samples }\end{array}$ & $\begin{array}{c}\text { Cassinari et al. } \\
\text { (2021). }\end{array}$ & $\begin{array}{c}\text { COVID-19 do tipo } \\
\text { multiplex RT- } \\
\text { ddPCR com } 6 \\
\text { conjuntos de primers } \\
\text { de sonda já } \\
\text { validados em } \\
\text { ensaios qPCR, e } \\
\text { então avaliar o } \\
\text { desempenho do } \\
\text { ensaio para a } \\
\text { detecção de SARS- } \\
\text { CoV-2 em } \\
\text { nasofaringe e } \\
\text { amostras de saliva } \\
\text { coletadas em uma } \\
\text { coorte de pacientes. }\end{array}$ & $\begin{array}{l}\text { Foi desenvolvido um } \\
\text { ensaio multiplex de } \\
\text { transcrição reversa } \\
\text { digital de gotículas PCR } \\
\text { (RT-ddPCR), visando } 6 \\
\text { regiões genômicas do } \\
\text { SARS- CoV-2, e material } \\
\text { coletado em nasofaringe } \\
\text { e amostras de saliva } \\
\text { coletadas de 130 } \\
\text { indivíduos com COVID- } \\
\text { 19, sendo esses pacientes } \\
\text { ambulatoriais positivos } \\
\text { ou negativos, que } \\
\text { apresentaram sintomas } \\
\text { sugestivos de infecção } \\
\text { por SARS- CoV-2 leve } \\
\text { ou moderada. }\end{array}$ & $\begin{array}{l}\text { obtidos com os ensaios 6-plex } \\
\text { RT-ddPCR e RT-qPCR foram } \\
\text { todos concordantes. O ensaio 6- } \\
\text { plex RT-ddPCR foi mais } \\
\text { sensível do que RT-qPCR }(85 \% \\
\text { versus } 62 \%) \text { em amostras de } \\
\text { saliva de pacientes com } \\
\text { esfregaços da região de } \\
\text { nasofaringe. }\end{array}$ & $\begin{array}{l}\text { ferramenta alternativa e } \\
\text { complementar para o } \\
\text { diagnóstico de COVID-19, } \\
\text { em particular para controlar } \\
\text { resultados ambíguos de } \\
\text { RT-qPCR. } \\
\text { Também pode ser aplicado } \\
\text { à saliva para amostragem e } \\
\text { teste repetitivos de } \\
\text { indivíduos para os quais o } \\
\text { esfregaço nasofaríngeo não } \\
\text { é possível. }\end{array}$ \\
\hline
\end{tabular}

Fonte: Autores.

\section{Discussão}

O presente estudo objetivou compilar evidências científicas atuais acerca da presença de SARS-CoV-2 em glândulas salivares e na saliva e discutir a relevância deste conhecimento na prática clínica odontológica. Esse tema assume grande relevância tendo em vista as crescentes "ondas" de infecções provocadas pelo vírus e suas variantes em todo o mundo e por permitir avaliar o potencial da saliva como meio de transmissão da doença e o desenvolvimento de testes diagnósticos menos invasivos. Recentemente, McCormick-Baw et al. (2020), demonstraram que o teste PCR Cepheid Xpert Xpress SARS-CoV-2 (Sunnyvale, CA) foi eficaz em detectar ácidos nucleicos do SARS-CoV-2 na saliva. Este resultado demonstra que a coleta da saliva para o diagnóstico de COVID-19 pode ser considerado um método opcional, não invasivo, rápido e eficaz, principalmente em locais em que há escassez de insumos para testes que são realizados com material coletado a partir da nasofaringe e que necessitam de alternativas para realização de exames diagnósticos.

Na presente revisão sistemática observou-se que Zhong et al. (2020) evidenciaram, em estudo com 49 pacientes adultos diagnosticados com COVID-19, uma significativa taxa de expressão do receptor ACE2 nas glândulas salivares, assim como uma contínua eliminação de SARS-CoV-2 e detecção de RNA de SARS-CoV-2 na saliva. Além disso, constataram que a taxa de detecção na saliva de $90,2 \%$ foi mais alta e mais sensível do que no esfregaço faríngeo (83,7\%), mucosa oral (49,0\%), mucosa retal $(63,6 \%)$ e amostras de sangue que se situaram em torno de 17,4\%. Estes dados se repetiram nas análises seriadas e também naquelas realizadas em um único momento de coleta. Foi constatado, através do presente levantamento da literatura, um único estudo que avaliou a presença do SARS-Cov-2 em saliva coletada diretamente do ducto de Wharton a fim de conseguir fluído estéril do canal das glândulas. Esta análise foi realizada por Chen et al. (2020), os quais demonstraram em seu estudo diagnóstico com 31 pacientes, que 13 deles tiveram resultado positivo para COVID-19 e 4 indivíduos apresentaram positividade nas amostras de saliva, os quais representaram $75 \%$ dos casos graves que necessitaram de intubação.

Vaz et al. (2020), em um estudo epidemiológico com 155 participantes, constataram que 96,1\% apresentaram RT-PCR positivo para SARS-CoV-2 tanto na saliva quanto nos esfregaços faríngeo e nasofaríngeo, sendo que o maior percentual de testes positivos foi constatado em material colhido da região faríngea e nasofaríngea. Além disso, ao utilizar como padrão-ouro o RTPCR de amostras faríngeas e nasofaríngeas para avaliar a especificidade e sensibilidade deste teste nas amostras de saliva, observou-se percentuais elevados da ordem de $97,62 \%$ e $94,4 \%$, respectivamente.

Azzi et al. (2020), avaliaram 25 pacientes e observaram que 2 destes apresentaram resultado positivo nas amostras de saliva no mesmo dia em que o material coletado dos esfregaços faríngeos ou broncoalveolares apresentaram resultados negativos. No estudo de acurácia diagnóstica de Tutuncu et al. (2021), que também utilizou o RT-PCR para o diagnóstico de SARS-CoV2 em amostras nasofaríngeas, com 53 pacientes, 90,56\% demonstraram positividade no RT-PCR para SARS-CoV-2 nas amostras 
de saliva. Tais estudos parecem indicar que a saliva pode ser um material biológico útil adicional para análise da presença do SARS-Cov-2, tanto em situação de infecção ativa, quanto em indivíduos assintomáticos.

Há crescente evidência na literatura que tem ratificado a presença do SARS-Cov-2 na saliva e nas glândulas salivares. Güçlü et al. (2020), em estudo prospectivo que acompanhou 64 participantes, documentaram detecção de SARS-CoV-2 na saliva em $42,2 \%$ da amostra. Cerca de $36 \%$ dos participantes apresentaram teste positivo tanto para o esfregaço oronasofaríngeo quanto para a amostra de saliva. Tal investigação também foi realizada por Wyllie et al. (2021). Estes autores realizaram um estudo prospectivo de coorte com 44 pacientes testados positivos para SARS-CoV-2 usando esfregaços nasofaríngeo e/ou orofaríngeo e saliva. Foi demonstrado também que os títulos de SARS-CoV-2 na saliva foram significativamente maiores do que na amostra nasofaríngea ao se analisar cada pacientes individualmente. Além disso, em 21\% das amostras foi detectado SARS-CoV-2 na saliva, mas não nos esfregaços nasofaríngeos. Resultados semelhantes foram descritos por Griesemer et al. (2021).

Adicionalmente, alguns outros estudos também têm procurado avaliar de forma comparativa a acurácia de testes diagnósticos em material biológico oriundo de esfregaços orofaríngeos e aquele representado pela saliva. Neste contexto, Moreno-Contreras et al. (2020), realizaram em estudo prospectivo de acurácia diagnóstica com 253 pacientes ambulatoriais com suspeita de infecção por COVID-19. Nesse sentido, um grupo de 182 pacientes foi submetido a um único esfregaço orofaríngeo e 80 testaram positivo para SARS-CoV-2. O teste com material orofaríngeo e nasofaríngeo, (82,3\%) demonstrou maior eficácia na detecção do vírus em relação ao material biológico salivar (73,5\%), com uma taxa de coincidência de 55,8\%. Resultados divergentes foram descritos por Herrera et al. (2021), através de estudo de coorte transversal com 2107 profissionais de saúde, no qual $98 \%$ dos testes mostraram resultados semelhantes com a saliva e o esfregaço nasofaríngeo. Além disso, a saliva apresentou menor percentual de resultados inconclusivos do que aqueles resultantes dos esfregaços nasofaríngeos. Percebe-se que ainda não existe um consenso na literatura sobre a acurácia dos diferentes tipos de testes existentes quando estes são realizados utilizando-se saliva.

Em virtude da alta variação das cargas virais encontradas em testes de RT-qPCR, a busca por novas formas de diagnóstico para Sars-Cov-2 foi desenvolvida, principalmente para diferentes regiões do genoma viral. Cassinari et al. (2021), em análise prospectiva de esfregaços nasofaríngeos e amostras de saliva usando o ensaio 6-Plex RT-ddPCR (BioRadLaboratories) para 130 pacientes, demonstraram que a sensibilidade dos ensaios moleculares para COVID-19 realizados em material biológico salivar foi significativamente menor em comparação aos esfregaços nasofaríngeos, pois a carga viral média foi 400 vezes menor na saliva. Além disso, foi demonstrado maior sensibilidade do ensaio multiplex RT-ddPCR (85\% (Bio-Rad Laboratories) em comparação com o RT-qPCR (62\%) para análises de saliva. Yamazaki et al. (2021), em estudo diagnóstico com 44 amostras de saliva provenientes de pacientes com suspeita de infecção por COVID-19 utilizaram o teste triplex RTLAMP realizado através de uma leitura colorimétrica a partir de um bloco de calor, com resultados avaliados a olho nu. Das amostras utilizadas, 23 tiveram resultados positivos e 21 tiveram resultados negativos pelo método de referência. A sensibilidade diagnóstica foi $82,6 \%$ e a especificidade de $100 \%$. A partir destes achados, pode-se sugerir que até o presente estágio da pandemia, o RT-PCR que processa material coletado da região nasofaríngea ainda continua sendo o teste mais usado para o diagnóstico da COVID-19 devido à sua acurácia e alta sensibilidade.

Contudo, devido à escassez de insumos para realização de esfregaços orofaríngeos e nasofaríngeos em diversos países, além da redução do desconforto dos pacientes, urge a necessidade de alternativas para diagnóstico de infecção pelo SARS-CoV2. Williams et al. (2020), em estudo diagnóstico, analisaram a viabilidade e a utilidade da coleta de saliva de 622 pacientes que foram testados positivos para COVID-19. O diagnóstico por meio das amostras salivares representou $84,6 \%$ dos resultados do PCR em esfregaços nasofaríngeos já positivados. Para avaliar a especificidade, também foi testado um subconjunto de amostras salivares de 50 pacientes com esfregaços nasofaríngeos PCR-negativos, o SARS-CoV-2 foi detectado em 2\% dessas amostras de saliva. Resultados semelhantes foram observados no estudo de McCormick-Baw et al. (2020), que buscaram validar amostras 
de saliva para o diagnóstico de COVID-19 utilizando o teste PCR Cepheid Xpert Xpress (Sunnyvale, CA) com saliva não conservada coletada no pronto-socorro. É relevante notar que, nesse estudo, houve percentual próximo para os resultados positivos (96\%) e negativos (99\%) dos esfregaços nasofaríngeos e do material biológico salivar. Evidências similares também foram encontradas por Sakanash et al. (2020).

A pandemia do SARS-CoV-2 revolucionou as práticas em diversas áreas da saúde e na Odontologia este efeito não foi diferente. Os cirurgiões-dentistas representam um grupo de profissionais de saúde que apresentam grande risco de contrair a COVID-19 assim como infecção cruzada pois lidam diretamente com aerossóis provenientes do fluxo salivar e secreção do trato respiratório. O uso de máscaras eficazes, álcool a 70\% e equipamentos para proteção individual (EPIs) tornaram-se fundamentais para diminuir a transmissão do SARS-CoV-2. Diversas autoridades internacionais sugeriram o uso de enxaguantes bucais como uma medida de controle de infecção pré-processual. Seneviratne et al. (2020), em estudo controle randomizado avaliaram a eficácia de três enxaguantes bucais: povidone-iodine (PI), cloroxidina gluconato (CHX) e cloreto de cetilítrio (CPC) em comparação com a água, na redução da carga viral salivar em pacientes com COVID-19. Foram selecionados 36 pacientes SARSCoV-2 positivos, dos quais 16 pacientes foram atribuídos de forma aleatória a quatro grupos. Os grupos submetidos ao uso de PI e CHX apresentaram diminuição da carga salivar após o uso desses colutórios bucais. Os autores sugeriram que o enxágue pré-processual pode ser útil para reduzir a transmissão da COVID-19.

Especificamente, para pacientes críticos, a saliva tem um potencial maior para deteç̧ão de SARS-CoV-2. Embora a detecção positiva de ácidos nucleicos em swab orofaríngeo seja um dos critérios diagnósticos para testes de COVID-19, profissionais de saúde estão expostos a risco de infecção durante a coleta de amostras. Além disso, a coleta de amostras de orofaringe pode causar desconforto aos pacientes, como dor, náusea e até mesmo sangramento. Portanto, o estudo da saliva pode ser uma nova fonte de diagnóstico, especialmente para pacientes críticos, uma vez que pode ser facilmente coletado sem quaisquer procedimentos invasivos, o que é vantajoso tanto para profissionais de saúde e pacientes, especialmente para amostragem múltipla e monitoramento das cargas virais (Chen et al., 2020).

Como a amostragem de saliva é um procedimento de coleta não invasivo, ela representa, como demonstrado por um número crescente de estudos, uma estratégia apropriada para testar indivíduos repetidamente (por exemplo, em asilos), para testar indivíduos para os quais os swabs nasofaríngeos são contraindicados, ou para testar grandes populações suspeitas de apresentarem alta carga viral (Cassinari et al., 2021). Além disso, a saliva pode ser auto recolhida pelo paciente com o mínimo de orientação e intervenção do pessoal de saúde (Azzi et al., 2020).

O teste de saliva pode ser um teste de triagem de primeira linha alternativo adequado em vários ambientes, incluindo configurações de baixo recurso, com teste nasofaríngeo reservado para pacientes com um alto índice clínico contínuo de suspeita. Essas descobertas são altamente relevantes em face da escassez de swabs e equipamentos de proteção em muitos ambientes (Williams et al., 2020). A detecção do vírus em saliva também tem sido usada para monitorar a dinâmica da carga viral ao longo do tempo, indicando que a maior carga viral na saliva se apresenta durante a primeira semana após o início dos sintomas e depois diminui ao longo do tempo (Herrera et al., 2021).

A amostragem de saliva também pode ser considerada como amostra suplementar em pacientes com testes negativos em swabs nasofaríngeos, mas com sintomas fortemente sugestivos de COVID-19. Os resultados falsos negativos de RT-qPCR podem estar relacionados a uma menor celularidade dos swabs nasofaríngeos para amostragem. Esta ideia é apoiada pela observação de que, em algumas amostras, o RT-ddPCR detectou uma concentração viral maior na saliva do que no swab nasofaríngeo (Cassinari et al., 2021). Os resultados falsos negativos na saliva podem ser devidos à ausência ou níveis indetectáveis de vírus nas amostras, ou a problemas durante a coleta, transporte e/ou armazenamento antes de sua chegada ao laboratório. Griesemer et al. (2021), encontraram surpreendente estabilidade do RNA viral na saliva por até 7 dias, mesmo em temperatura ambiente, enquanto a adição de soluções de estabilização teve efeitos adversos. A estratégia de amostragem de 
saliva tem limitações: pode não ser adequada para crianças, pacientes com deficiência mental ou pacientes graves. A coleta de saliva claramente não é adequada para pacientes intubados, e o uso de tipos alternativos de amostras deve ser continuado para essas situações.

Desde o início da pandemia, tem havido uma preocupação crescente com o risco da transmissão do SARS-CoV-2 na prática odontológica. Profissionais de saúde bucal estão expostos a aerossóis da cavidade oral dos pacientes, o que pode ser um risco potencial para equipe e talvez outros pacientes (Seneviratne et al., 2020). Assim, além de medidas de proteção rigorosas, reduzir os títulos virais salivares em pacientes com COVID-19, através do uso de enxaguantes bucais, por exemplo, pode ser uma das principais abordagens para evitar a transmissão de COVID-19, particularmente em ambientes odontológicos.

\section{Conclusão}

Estudos de acurácia diagnóstica e prospectivos, estudos de corte transversal, coorte, ensaios clínicos randomizados e não randomizados, incluídos na presente revisão sistemática, revelaram evidências científicas atuais acerca da presença de SARS-CoV-2 em glândulas salivares e na saliva. Este conhecimento assume grande relevância para a prática clínica odontológica. Foi constatada a eficácia do RT-PCR com material salivar para detecção do SARS-CoV-2, semelhante aos testes baseados em esfregaços orofaríngeos e nasofaríngeos, principalmente no diagnóstico de pacientes assintomáticos, embora essa discussão ainda seja incipiente na comunidade científica internacional. A detecção de SARS-CoV-2 na saliva demostrou ser uma alternativa segura e de fácil exequibilidade para obtenção de dados qualitativos em relação ao vírus e informações sobre o curso clínico da doença, todavia, mais estudos precisam ser realizados, com o objetivo futuro de implementação desta técnica facilitadora para obtenção do diagnóstico de COVID-19, de forma segura e eficaz.

\section{Referências}

Azzi, L., Carcano, G., Gianfagna, F., Grossi, P., Gasperina, D. D., Genoni, A., \& Baj, A. (2020). Saliva is a reliable tool to detect SARS-CoV-2. Journal of Infection, 81(1), e45-e50. https://doi.org/10.1016/j.jinf.2020.04.005

Benvenuto, D., Giovanetti, M., Ciccozzi, A., Spoto, S., Angeletti, S., \& Ciccozzi, M. (2020). The 2019-new coronavirus epidemic: evidence for virus evolution. Journal of Medical Virology. 92(4), 455-459. https://doi.org/10.1002/jmv.25688

Burgueño-Rodríguez, G., Méndez, Y., Olano, N., Dabezies, A., Bertoni, B., Souto, J., \& Soler, A. M. (2020). Ancestry and TPMT-VNTR Polymorphism: relationship with hematological toxicity in uruguayan patients with Acute lymphoblastic leukemia. Frontiers in Pharmacology, 11, 1-8. https://doi.org/10.3389/fphar.2020.594262

Cassinari, K., Alessandri-Gradt, E., Chambon, P., Charbonnier, F., Gracias, S., Beaussire, L., \& Frebourg, T. (2021). Assessment of multiplex digital droplet RT-PCR as a diagnostic tool for SARS-CoV-2 detection in nasopharyngeal swabs and saliva samples. Clinical Chemistry, 67(5), 736-741. https://doi.org/10.1093/clinchem/hvaa323

Chen, L., Zhao, J., Peng, J., Li, X., Deng, X., Geng, Z., \& Wang, S. (2020). Detection of SARS-CoV-2 in saliva and characterization of oral symptoms in COVID-19 patients. Cell Proliferation, 53(12), e12923. https://doi.org/10.1111/cpr.12923

Chowdhury, P., Paul, S. K., Kaisar, S., \& Moktadir, A. (2021). COVID-19 pandemic related supply chain studies: A systematic review. Transportation Research Part E: Logistics and Transportation Review, 148, 102271. https://doi.org/10.1016/j.tre.2021.102271

Griesemer, S. B., Slyke, G. V., Ehrbar, D., Strle, K., Yildirim, T., Centurioni, D. A., \& George, K. S. (2021). Evaluation of specimen types and saliva stabilization solutions for SARS-CoV-2 testing. Journal of Clinical Microbiology, 59(5), e01418-e01420. https://doi.org/10.1128/JCM.01418-20

Güçlü, E., Koroglu, M., Yürümez, Y., Toptan, H., Kose, E., Güneysu, F., \& Karabay, O. (2020). Comparison of saliva and oro-nasopharyngeal swab sample in the molecular diagnosis of COVID-19. Revista da Associação Médica Brasileira, 66(8), 1116-1121. https://doi.org/10.1590/1806-9282.66.8.1116

Herrera, L. A., Hidalgo-Miranda, A., Reynoso-Noverón, N., Meneses-García, A. A., Mendoza-Vargas, A., Reyes-Grajeda, J. P., \& Escobar-Escamilla, N. (2021). Saliva is a reliable and accessible source for the detection of SARS-CoV-2. International Journal of Infectious Diseases, 105, 83-90. https://doi.org/10.1016/j.ijid.2021.02.009

Hoffmann, M., Kleine-Weber, H., Schroeder, S., Krüger, N., Herrler, T., Erichsen, S., \& Pöhlmann, S. (2020). SARS-CoV-2 Cell Entry Depends on ACE2 and TMPRSS2 and Is blocked by a clinically proven protease inhibitor. Cell, 181(2), 271-280. https://doi.org/10.1016/j.cell.2020.02.052 
Research, Society and Development, v. 11, n. 3, e45111326673, 2022

(CC BY 4.0) | ISSN 2525-3409 | DOI: http://dx.doi.org/10.33448/rsd-v11i3.26673

Huang, C., Wang, Y., Li, X., Ren, L., Zhao, J., Hu, Y., \& Cao, B. (2020). Clinical features of patients infected with 2019 novel coronavirus in Wuhan, China. The Lancet, 395(10223), 497-506. https://doi.org/10.1016/s0140-6736(20)30183-5

McCormick-Baw, C., Morgan, K., Gaffney, D., Cazares, Y., Jaworski, K., Byrd, A., \& Cavuoti, D. (2020). Saliva as an alternate specimen source for detection of SARS-CoV-2 in symptomatic patients using Cepheid Xpert Xpress SARS-CoV-2. Journal of clinical microbiology, 58(8), e01109-20. https://doi.org/10.1128/jcm.01109-20

Moreno-Contreras, J., Espinoza, M. A., Sandoval-Jaime, C., Cantú-Cuevas, M. A., Barón-Olivares, H., Ortiz-Orozco, O. D., \& López, S. (2020). Saliva sampling and its direct lysis, an excellent option to increase the number of SARS-CoV-2 diagnostic tests in settings with supply shortages. Journal of Clinical Microbiology, 58(10), e01659. https://doi.org/10.1128/jcm.01659-20

Sakanashi, D., Asai, N., Nakamura, A., Miyazaki, N., Kawamoto, Y., Ohno, T., \& Mikamo, H. (2021). Comparative evaluation of nasopharyngeal swab and saliva specimens for the molecular detection of SARS-CoV-2 RNA in Japanese patients with COVID-19. Journal of Infection and Chemotherapy, 27(1), 126129. https://doi.org/10.1016/j.jiac.2020.09.027

Seneviratne, C. J., Balan, P., Ko, K. K. K., Udawatte, N. S., Lai, D., Ng, D. H. L., \& Sim, X. Y. J. (2021). Efficacy of commercial mouth-rinses on SARS-CoV2 viral load in saliva: randomized control trial in Singapore. Infection, 49(2), 305-311. https://doi.org/10.1007/s15010-020-01563-9

Song, J. W., Zhang, C., Fan, X., Meng, F. P., Xu, Z., Xia, P., \& Zhang, J. Y. (2020). Immunological and inflammatory profiles in mild and severe cases of COVID-19. Nature Communications, 11(1), 1-10. https://doi.org/10.1038/s41467-020-17240-2

Tutuncu, E. E., Ozgur, D., \& Karamese, M. (2021). Saliva samples for detection of SARS-CoV-2 in mildly symptomatic and asymptomatic patients. Journal of Medical Virology, 93(5), 2932-2937. https://doi.org/10.1002/jmv.26821

Vaz, S. N., Santana, D. S. de, Netto, E. M., Pedroso, C., Wang, W. K., Santos, F. D. A., \& Brites, C. (2020). Saliva is a reliable, non-invasive specimen for SARS-CoV-2 detection. The Brazilian Journal of Infectious Diseases, 24(5), 422-427. https://doi.org/10.1016/j.bjid.2020.08.001

Williams, E., Bond, K., Zhang, B., Putland, M., \& Williamson, D. A. (2020). Saliva as a non-invasive specimen for detection of SARS-CoV-2. Journal of Clinical Microbiology, 58(8), e00776. https://doi.org/10.1128/jcm.00776-20

Wyllie, A. L., Fournier, J., Casanovas-Massana, A., Campbell, M., Tokuyama, M., Vijayakumar, P., \& Grubaugh, A. I. (2020). Saliva is more sensitive for SARS-CoV-2 detection in COVID-19 patients than nasopharyngeal swabs. New England Journal of Medicine, 1-12. https://doi.org/10.1101/2020.04.16.20067835

Yamazaki, W., Matsumura, Y., Thongchankaew-Seo, U., Yamazaki, Y., \& Nagao, M. (2021). Development of a point-of-care test to detect SARS-CoV-2 from saliva which combines a simple RNA extraction method with colorimetric reverse transcription loop-mediated isothermal amplification detection. Journal of Clinical Virology, 136, 104760. https://doi.org/10.1016/j.jcv.2021.104760

Zhong, F., Liang, Y. J., Xu, J. B., Chu, M., Tang, G. F., Hu, F. Y., \& Liao, G. Q. (2020). Continuously high detection sensitivity of saliva, viral shedding in salivary glands and high viral load in patients with COVID-19. The Lancet, (20), 1-23. https://doi.org/10.2139/ssrn.3576869 